Revista Brasileira de Informática na Educação - RBIE Brazilian Journal of Computers in Education (ISSN online: 2317-6121; print: 1414-5685) http://br-ie.org/pub/index.php/rbie

Submission: 20/09/2020;

Camera ready: 12/01/2021; $1^{\text {st }}$ round notif: $03 / 11 / 2020$;

Edition review: 18/01/2021;
New version: $02 / 12 / 2020$;

Available online: 23/01/2021; $2^{\text {nd }}$ round notif:: 05/01/2021; Published: 23/01/2021;

\title{
Customização da Regulação Emocional de Acordo com a Personalidade dos Estudantes em Sistemas Tutores Inteligentes
}

\section{Title: Customization of Emotional Regulation According to the Personality of Students in Intelligent Tutoring Systems}

\author{
Helena Macedo Reis \\ Universidade Federal do Paraná \\ Campus Avançado de Jandaia do Sul, Paraná, Brasil \\ helena.macedo@ufpr.br
}

Patrícia A. Jaques

Universidade do Vale do Rio dos Sinos - PPGCA

São Leopoldo, Rio Grande do Sul, Brasil

pjaques@unisinos.br

\author{
Danilo Alvares \\ Pontificia Universidad Católica de Chile \\ Macul, Santiago, Chile \\ dalvares@mat.uc.cl \\ Seiji Isotani \\ Universidade de São Paulo - ICMC \\ São Carlos, São Paulo, Brasil \\ sisotani@icmc.usp.br
}

\begin{abstract}
Resumo
As emoções influenciam os processos cognitivos e são essenciais durante o aprendizado. Algumas emoções podem afetar negativamente o aprendizado, como a frustração e o tédio; outras, como o engajamento, podem ter um efeito positivo. Por outro lado, algumas emoções, como a confusão, podem ter um papel duplo, influenciando negativamente ou positivamente. A confusão ocorre quando há discrepâncias entre a informação recebida e as estruturas mentais do indivíduo ou quando há inconsistências no fluxo de informação. Quando experimentam confusão, os estudantes podem se sentir incentivados a buscar seu próprio conhecimento, através do foco e atenção na atividade, resultando em um impacto positivo no aprendizado. No entanto, quando sentem a confusão por um longo período e não conseguem resolvê-la, a confusão pode gerar uma sobrecarga cognitiva nos estudantes e levar a emoções mais negativas à aprendizagem, tais como frustração e tédio. Além disso, o tempo que os estudantes conseguem lidar com a confusão é influenciado por seu traço de personalidade e conhecimentos prévios sobre o assunto. Portanto, a confusão deve ser regulada para maximizar o aprendizado, promovendo um maior envolvimento, e evitar o abandono do exercício ou conteúdo. O problema investigado neste trabalho é como e quando um sistema inteligente de tutoria poderia apoiar a regulação da confusão quando sentida por um longo período por um estudante. Para isso, foi desenvolvido um algoritmo com o objetivo de apoiar na escolha de elementos multimídia (por exemplo, vídeo, figura ou texto) para regular a confusão. A escolha dos elementos considera o conhecimento prévio do estudante e são apresentados de acordo com seu nível de detalhamento (por exemplo, de elementos com poucos detalhes de resolução a elementos apresentados com muitos detalhes). Além disso, quanto tempo o algoritmo espera para regular a confusão do estudante considera a sua personalidade. Para avaliar o algoritmo desenvolvido, foi realizado um experimento com estudantes $(N=111)$ do ensino fundamental e superior de duas escolas e uma faculdade, durante três meses. Foram analisadas a capacidade do algoritmo de influenciar na regulação da confusão durante a resolução de equações de primeiro grau em um Sistema Tutor Inteligente (PAT2Math), em indivíduos com personalidades de extroversão e neuroticismo. Os resultados mostram que os estudantes que usaram o PAT2Math com o algoritmo desenvolvido de regulação de confusão (grupo experimental) cometeram menos erros e resolveram os exercícios mais rapidamente do que os estudantes que não receberam assistência com relação à regulação de confusão. Os resultados indicam que o sistema estaria regulando a confusão ou emoção negativa decorrente da confusão.
\end{abstract}

Palavras-chave: Sistemas Tutores Inteligentes; Regulação da Frustração; Regulação da Emoção.

Cite as: Reis, H. A., Alvares, D., Jaques, P. A. \& Isotani, S. (2021). Customization of Emotional Regulation According to the Personality of Students in Intelligent Tutoring Systems (Customização da Regulação Emocional de Acordo com a Personalidade dos Estudantes em Sistemas Tutores Inteligentes). Brazilian Journal of Computers in Education (Revista Brasileira de Informática na Educação - RBIE), 29, 48-72. DOI: 10.5753/RBIE.2021.29.0.48. 


\begin{abstract}
Emotions influence cognitive processes and are essential during learning. Some emotions can negatively affect learning, as frustration and boredom; others, such as engagement, can positively affect. On the other hand, confusion can influence either negatively or positively. When students experience confusion, they may feel encouraged to seek their knowledge through focus and attention on the activity, resulting in a positive impact on learning. However, when they feel it for an extended period and cannot deal with it, the confusion can generate a cognitive overload on the students and increases the chances of the student to reject the subject that is being learned. Besides, the students' personality and their previous knowledge on the subject influence the time they can deal with confusion. Therefore, the confusion must be regulated to maximize learning, promoting a more significant engagement and preventing the abandonment of the exercise or content. The problem investigated by this work is how and when an Intelligent Tutoring System could support the regulation of confusion when felt for an extended period by a student. For this purpose, we developed an algorithm to support the choice of multimedia elements (video, figure, or text) to regulate confusion. The choice of the elements considers the student's personality traits and previous knowledge on the subject. To evaluate our algorithm, we have conducted an experiment with students $(N=111)$ from elementary and higher education from two schools and a college for three months. We analyzed the algorithm's capacity to influence the regulation of confusion during first-degree equations solving in an Intelligent Tutoring System (PAT2Math) in subjects with extroversion and neuroticism personalities. The results show that the students who used the PAT2Math with our confusion regulation algorithm (experimental group) made fewer mistakes and solved the exercises more quickly than students who have not received any assistance regarding confusion regulation. The results indicate that the system would be regulating the confusion or negative emotions that happens after it.
\end{abstract}

Keywords: Intelligent Tutoring Systems; Frustration Regulation; Emotional Regulation.

\title{
1 Introdução
}

As emoções ${ }^{1}$ se revelam essenciais durante a aprendizagem (Pessoa, 2008; Schutz \& Lanehart, 2002). Elas são capazes de possibilitar ou inibir a aprendizagem (Greenleaf, 2002) por meio da categorização, do pensamento e da resolução de problemas (Sutton \& Wheatley, 2003), além de influenciar no aumento da atenção dos estudantes, bem como melhorar a memória e o raciocínio (Oxford \& Bolaños-Sánchez, 2016).

Alguns estudos (Graesser, Chipman, Haynes, \& Olney, 2005; D’Mello, Graesser, et al., 2007) sugerem que as emoções como confusão, frustração, tédio e engajamento ocorrem continuamente durante a experiência de aprendizado em ambientes computacionais. Dentre estas emoções, a frustração e o tédio impactam negativamente ${ }^{2}$ na aprendizagem, enquanto o engajamento influencia de forma positiva ${ }^{3}$ (D’Mello, Graesser, et al., 2007). Por sua vez, a confusão pode ter um papel duplo: pode desencadear engajamento ou resistência ao processo de aprendizagem (D’Mello, Person, \& Lehman, 2009).

Particularmente, a confusão é um estado afetivo importante para estudo científico na

\footnotetext{
${ }^{1}$ Segundo Scherer (2005), as emoções são definidas como respostas às situações que são percebidas como relevantes para avaliação de um evento interno ou externo de maior importância. Raiva, tristeza, alegria, medo, vergonha, orgulho e desespero são exemplos de emoções.

${ }^{2}$ Podem reduzir a memória de trabalho (sistema de memória usado para manter e manipular informações por um curto período enquanto várias tarefas mentais são executadas (Allport \& Leite, 1966; Cattell \& P. Cattell, 1995)) e a probabilidade dos estudantes usarem estratégias cognitivas para um processamento de informação mais profundo e mais elaborado (Linnenbrink \& Pintrich, 2000).

${ }^{3}$ Melhora a capacidade de resolver problemas e a tomada de decisões, além de facilitar a recordação de informações afetivamente neutras e positivas (Estrada, Isen, \& Young, 1994).
} 
aprendizagem (Rozin \& Cohen, 2003). A confusão é classificada como uma emoção cognitiva ou emoção do conhecimento (knowledge emotion em inglês), pois ela ocorre quando há discrepâncias entre a informação recebida e as estruturas mentais do indivíduo ou quando há inconsistências no fluxo de informação (information stream) (D’Mello, Lehman, Pekrun, \& Graesser, 2014). A confusão pode ser benéfica à aprendizagem quando o estudante se engaja em atividades cognitivas para resolver esse desequilíbrio cognitivo, e portanto, a sua confusão. Caso contrário, o estudante pode passar a experimentar emoções negativas, tais como frustração e tédio, mais relacionadas à resistência ao aprendizado e baixo desempenho e, portanto, negativas à aprendizagem (D'Mello et al., 2014).

Quando a confusão é experimentada por pouco tempo (ou confusão leve) indica que o estudante está integrando todas as novas informações com o seu conhecimento e habilidades existentes, sendo positiva para o aprendizado. Porém, quando a confusão é experimentada por longo período de tempo (ou confusão profunda), ela pode levar o estudante a abandonar o exercício ou material que está sendo estudado (Lehman et al., 2013). Para diversas pesquisas (Rodrigo, Baker, \& Nabos, 2010), quanto mais tempo um estudante permanecer confuso, menos provável que ele seja capaz de resolver essa confusão. Desta maneira, a confusão é uma emoção que não deve ser suprimida quando surge, pois pode influenciar de forma positiva no aprendizado ao engajar o estudante em atividades cognitivas para resolver seu impasse mental. Entretanto, quando o estudante não consegue lidar com essa confusão, ela deve ser regulada para não impactar negativamente no aprendizado.

Para auxiliar os estudantes a lidarem com a confusão a fim de desencadear o engajamento e evitar a resistência ao processo de aprendizagem, diversas pesquisas apontam a importância da regulação emocional, particularmente, da confusão, durante o ensino com o suporte computacional (Arguedas, Daradoumis, \& Xhafa, 2016). A regulação emocional refere-se à capacidade de gerenciar o estado emocional por meio do monitoramento, da avaliação e da modificação das respostas emocionais (Thompson, 1991) com objetivo de promover bem estar pessoal.

Alguns estudos apontam a existência de uma associação positiva entre traços da personalidade e o tempo de tolerância em sentir uma emoção (D'Mello, Graesser, et al., 2007; Reis, Jaques, \& Isotani, 2018), indicando que determinadas características influenciam no tempo de permanência em uma emoção. Nesse sentido, Reis, Jaques, and Isotani (2018) apresentaram resultados que sugerem que indivíduos com traço de personalidade de neuroticismo possuem menos tolerância a sentir confusão por longo período de tempo, comparado aos estudantes com personalidade de extroversão. Quando sentida por longo período, a probabilidade do estudante com alta pontuação em neuroticismo sentir frustração ou tédio aumenta significativamente. Esses resultados sugerem que para um estudante que possui uma personalidade de neuroticismo (tendências para emoções negativas) e seja iniciante no assunto ou a tarefa seja complexa, a confusão deve ser gerenciada cautelosamente.

Desta forma, um ambiente inteligente de aprendizagem deve buscar regular a emoção do estudante de forma que não induza ou permita que um estudante que apresenta personalidade de neuroticismo e iniciante no assunto sinta confusão por um longo período de tempo, principalmente em tarefas complexas (que exigem alto conhecimento ou envolvimento cognitivo), pois esta confusão pode levar à frustração e/ou tédio (D’Mello, Graesser, et al., 2007). Por outro lado, estudantes que possuem personalidade de extroversão conseguem tolerar a confusão por mais 
tempo (Reis, Jaques, \& Isotani, 2018), e consequentemente envolvem-se em atividades cognitivas por mais tempo, realizam mais conexões mentais e relacionam com conhecimento prévio por mais tempo.

Dentro desse contexto, a questão de pesquisa a ser investigada neste trabalho é: A regulação emocional baseada na personalidade do estudante e no seu conhecimento apoia o estudante a lidar com a confusão? Mais especificamente, estamos interessados em verificar qual o impacto dessa regulação no desempenho do estudante, tais como o número de erros realizados e no tempo de resolução dos problemas. Desta forma, o objetivo de pesquisa é propor um modelo para regulação da confusão do estudante considerando a sua personalidade e conhecimento prévio, antes que o estudante comece a sentir frustração/tédio.

O restante deste trabalho está organizado da seguinte forma: na Seção 2 é apresentada uma análise dos trabalhos relacionados. Na Seção 3 é apresentada a proposta de Regulação Emocional Personalizada para Sistemas Tutores Inteligentes por meio de traços de personalidade. A Seção 4 descreve o método desta pesquisa, como o objetivo, hipótese, design e a análise da prova de conceito para avaliação desta proposta. Na Seção 5 e 6 é apresentada a discussão e ameaças à validade, respectivamente. Finalmente, na Seção 7, são apresentadas as conclusões do trabalho acompanhadas das considerações.

\section{Trabalhos Relacionados}

O estudo de Reis, Alvares, Jaques, and Isotani (2018) apresentou os resultados de um mapeamento sistemático de como os sistemas inteligentes de aprendizagem regulam as emoções dos estudantes. Este mapeamento apontou que há várias abordagens de interação nas interfaces dos sistemas educacionais para a regulação emocional dos estudantes. Por exemplo, o estudo de Desseilles (2016) utilizou a abordagem de "Serious Games" para a regulação, na qual as estratégias de regulação são baseadas na teoria de regulação emocional de Gross (1998). No jogo, ao se sentir triste, acontece uma personalização diferente, por meio da música, cenários e elementos a fim de regular a emoção do estudante.

Além da interação usando Serious Games, a teoria de regulação da emoção de Gross (1998) é também utilizada nos meios de interação baseada em agentes pedagógicos e realidade virtual. No estudo de Bosse, Gerritsen, De Man, and Treur (2012), o agente pedagógico foi usado para auxiliar o estudante a direcionar a atenção em elementos apresentados na interface, caso ele se sentisse com tédio. Quando houvesse uma falha, o agente pedagógico apoiava o estudante a reavaliar a sua emoção atual usando mensagens motivacionais.

$\mathrm{Na}$ interação por realidade virtual, o estudo de Nararro-Haro et al. (2016) consistiu em usar a estratégia de reavaliação cognitiva por meio da técnica de mindfulness ${ }^{4}$ mostrando imagens com paisagens, na qual levava o estudante a um estado de relaxamento. A realidade virtual também foi utilizada para o enfrentamento de situações de estresse, com a teoria proposta por Lazarus (1993). No estudo de Gaggioli et al. (2011), o indivíduo foi exposto a um mundo virtual, proporcionando imersão e vivência de situações estressantes para aprender a lidar com

\footnotetext{
${ }^{4} \mathrm{O}$ termo mindfulness é definido por ser um estado de atenção plena no momento presente de forma intencional e sem julgamentos (Kabat-Zinn et al., 1998).
} 
suas emoções e relaxar durante momentos de tensão. Além da teoria proposta por Lazarus (1993), a estratégia de regulação emocional de inoculação de estresse de Meichenbaum também utiliza métodos de relaxamento (por exemplo, visualização de paisagens de natureza) para que o indivíduo consiga enfrentar a situação de estresse presente na realidade virtual (Pallavicini et al., 2013).

Alternativamente, alguns estudos adotam a interação textual para aplicar a abordagem Aprendizagem Colaborativa Apoiada por Computador e a recomendação para a regulação emocional (Tian et al., 2014; Xu, Du, \& Fan, 2013; Bakhtiar, Webster, \& Hadwin, 2018). Baseado em trabalho colaborativo, os indivíduos de um grupo, como colegas e instrutores, poderiam auxiliar, por meio de feedback, outros membros que apresentassem estresse e ansiedade. Na abordagem de recomendação, quando o sistema detectava a frustração, era apresentada uma mensagem motivacional na qual informava que errar é comum e era necessário um esforço na próxima tentativa.

O resultados do estudo de Reis, Alvares, et al. (2018) demonstraram que os trabalhos não consideram aspectos que afetam na regulação emocional, como por exemplo conhecimento prévio, histórico durante o uso do sistema ou os traços de personalidade. A regulação emocional está intimamente relacionada com aspectos particulares de cada indivíduo. No contexto educacional, a regulação emocional é afetada pelo conhecimento do estudante no assunto, a emoção que ele está vivenciando no momento da aprendizagem e seu traço de personalidade (D’Mello, Picard, \& Graesser, 2007). Uma das maneiras de descobrir o conhecimento do indivíduo é por meio do seu desempenho ao solucionar os problemas propostos. Supõem-se que quanto mais o indivíduo acerta os problemas apresentados, mais conhecimento ele tem sobre o tema. Porém, a cognição (ou a capacidade de resolver problemas) é afetada pelas emoções e personalidade do indivíduo, na qual, caso ele tenha tendências (e.g. personalidade neuroticismo) a emoções negativas (i.e. tédio ou frustração), seu desempenho é impactado negativamente caso ele esteja experimentando uma emoção negativa. Além disso, os resultados do estudo de Reis, Alvares, et al. (2018) também demonstraram que não houve trabalhos que investigaram o gerenciamento da confusão, como por exemplo, o momento mais adequado para intervir na confusão do estudante e ajudá-lo a resolver esse desequilíbrio cognitivo. Por ser uma lacuna de pesquisa, o presente estudo tem o objetivo de investigar a regulação emocional em Sistemas Tutores Inteligentes (STIs) no momento mais adequado, considerando o conhecimento prévio, histórico de uso do sistema e os traços de personalidade do estudante.

\section{Proposta de Regulação Emocional Personalizada para Sistemas Tutores Inteligentes por Meio de Traços de Personalidade}

A confusão é uma emoção que não deve ser evitada no contexto de aprendizagem (Craig, Graesser, Sullins, \& Gholson, 2004; D’Mello, Picard, \& Graesser, 2007), pois pode incentivar os estudantes a buscarem o seu próprio conhecimento, a manterem o foco e a atenção na atividade (D'Mello \& Calvo, 2013). Entretanto, quando a confusão não é resolvida, os estudantes precisam se envolver em atividades cognitivas para regulá-la, com objetivo de errarem menos e sentirem menos frustração e tédio. Essa regulação deve considerar as caraterísticas pessoais do estudante, como a personalidade e o conhecimento prévio, para determinar o tempo que esse estudante consegue 
tolerar a confusão, antes que torne-se uma emoção que impacte negativamente no aprendizado, além apresentar o elemento de multimídia mais adequado que irá auxiliar na sua cognição.

Desta maneira, descreve-se a seguir em qual momento a confusão deve ser regulada nos Sistemas Tutores Inteligentes (STIs) e de qual maneira ela deve ser regulada. Os Sistemas Tutores Inteligentes (STIs) são sistemas computacionais criados com objetivo de imitar o método de instrução individualizada, em que há um professor particular para cada aluno (ou one-to-one), buscando os melhores impactos positivos na aprendizagem que esse tipo de instrução fornece (VanLehn, 2011).

\subsection{Quando a Confusão Deve Ser Regulada nos STIs?}

Durante o processo de ensino-aprendizagem, o estudante pode experimentar várias emoções, como engajamento/flow, confusão, frustração e tédio. Através de estímulos, essas emoções podem ser alteradas conforme um fluxo, como por exemplo, uma pessoa que está sentindo confusão, pode passar a sentir frustração e tédio.

Nesse sentido, D’Mello, Graesser, et al. (2007) investigaram o fluxo das emoções (Tabela 1) durante a aprendizagem. Na Tabela 1, a transação esperada entre as emoções é simbolizada pelo sinal (+). A coluna Tempo $t_{i}$ apresenta as emoções iniciais e a coluna Tempo $t_{i}+1$ representa as emoções resultantes do fluxo. Desta maneira, os resultados de seu estudo sugeriram que quando um estudante estava sentindo confusão (ver coluna Tempo $t_{i}$ ), havia uma alta probabilidade dele sentir outras duas emoções: flow/engajamento e frustração (ver coluna Tempo $t_{i}+1$ ). Se a duração da confusão não fosse adequadamente monitorada, o estudante poderia passar a sentir frustração e, em seguida, tédio (D’Mello, Graesser, et al., 2007). A frustração e o tédio estão relacionados negativamente com a aprendizagem, podendo levar o estudante a abandonar o exercício proposto ou evitar novos desafios (Reis, Jaques, \& Isotani, 2018). Por outro lado, o estudo demonstrou que não há resultados significativos que indicam uma relação explícita da transição de tédio para frustração, assim como de frustração para confusão.

Tabela 1: Fluxo das emoções durante o aprendizado (Traduzido de D'Mello, Graesser, et al. (2007))

\begin{tabular}{|c|c|c|c|c|}
\hline \multirow{2}{*}{ Tempo $t_{i}$} & \multicolumn{4}{|c|}{ Tempo $t_{i}+1$} \\
\cline { 2 - 5 } & Tédio & Engajamento & Confusão & Frustração \\
\hline Tédio & & - & - & $?$ \\
\hline Engajamento & - & & + & - \\
\hline Confusão & - & + & & + \\
\hline Frustração & + & - & $?$ & \\
\hline
\end{tabular}

(+) Indica que a transição é esperada.

(-) Indica que a transição é altamente improvável.

(?) Indica que não há relação explícita no modelo.

Os resultados desse estudo também sugeriram que no momento que o estudante experimentasse emoções negativas (tédio e frustração), eles tendiam a permanecer neste estado em vez de transitar para estados emocionais positivos, como flow. Por outro lado, estudantes 
Tabela 2: Média posterior do tempo mediano do tempo de permanência do estado emocional confusão para frustração/tédio para diferentes perfis (Traduzido de Reis, Alvares, et al. (2018))

\begin{tabular}{|l|l|l|l|l|l|l|l|l|l|}
\cline { 2 - 12 } \multicolumn{1}{c|}{} & \multicolumn{9}{c|}{ Perfil } \\
\hline Variável & P1 & P2 & P3 & P4 & P5 & P6 & P7 & P8 & P9 \\
\hline Conhecimento em álgebra & 0 & 0.5 & 1 & 0 & 0 & 1 & 1 & 0 & 1 \\
\hline Índice de neuroticismo & 0 & 0.5 & 0 & 1 & 0 & 1 & 0 & 1 & 1 \\
\hline Índice de extroversão & 0 & 0.5 & 0 & 0 & 1 & 0 & 1 & 1 & 1 \\
\hline Tempo (s) & 34 & 76 & 159 & 19 & 64 & 90 & 313 & 37 & 175 \\
\hline
\end{tabular}

no estado flow tendiam a se manter engajados ou transitaram alternadamente para confusão, um estado emocional que pode ser correlacionado positivamente com a aprendizagem (D'Mello, Graesser, et al., 2007).

O fluxo de uma emoção para outra pode depender de vários fatores, incluindo traços de personalidade e o seu nível de conhecimento anterior (Reis, Jaques, \& Isotani, 2018; D’Mello, Picard, \& Graesser, 2007). Assim, o estudo de Reis, Alvares, et al. (2018) investigou como especificamente a personalidade e o conhecimento prévio dos estudantes afetam o tempo de permanência em um estado de confusão. No estudo, os autores aplicaram um questionário para identificar os traços de personalidade e um pré-teste para determinar o conhecimento prévio. Os resultados sugeriram que o conhecimento prévio em álgebra e os traços de personalidade afetaram o tempo de permanência entre os estados emocionais de confusão e frustração/tédio no processo de aprendizagem.

Por meio da análise Bayesiana, utilizando modelo de riscos proporcionais Weibull e função de sobrevivência, os autores notaram que estudantes com alto índice de neuroticismo e baixa nota de conhecimento de álgebra não conseguiram permanecer muito tempo sentindo confusão, e logo vivenciaram emoções negativas, como frustração e tédio. Por outro lado, estudantes com alto índice de extroversão e baixo desempenho no conhecimento de álgebra permaneceram mais tempo sentindo confusão.

A Tabela 2 apresenta a média posterior do tempo mediano (valor que demonstra que metade dos valores do conjunto de dados está abaixo dele e a outra metade está acima) do tempo de permanência do estado emocional confusão para frustração/tédio com diferentes perfis de estudantes, considerando os níveis de conhecimento prévio em álgebra e pontuações dos índices de neuroticismo e extroversão.

A partir dos resultados apresentados na Tabela 2, é possível verificar a influência de cada variável no tempo mediano do tempo de permanência do estado emocional confusão para frustração/tédio. Por exemplo, o perfil 2 (P2) apresenta uma configuração "mediana" (0.5) para todas as variáveis. Em média, este perfil levaria 76 segundos da confusão para frustração/tédio. Quando o estudante possui a pontuação do teste prévio em álgebra (1.0) e pontuação mínima no índice de extroversão (0.0), o estudante levaria 313 segundos da confusão para frustração/tédio (P3). Por outro lado, quando o estudante tem pontuação máxima no índice de neuroticismo e mínima no teste prévio de álgebra e no índice de extroversão, em média, seu tempo é de 19 segundos (P4).

Os autores deste presente trabalho acreditam que os resultados preliminares do estudo de 
Reis, Alvares, et al. (2018) podem sugerir quando a regulação emocional deve ser acionada. Estas informações podem contribuir no controle da emoção utilizando interfaces adaptáveis, que detectam os traços de personalidade e o tempo de permanência da emoção confusão, adaptando a assistência para os estudantes iniciantes com pouca tolerância na permanência de confusão.

\subsection{Como a Regulação da Confusão Deve Acontecer em STIs?}

A confusão ocorre durante um desiquilíbrio cognitivo (Craig et al., 2004), indicando que há uma inconsistência entre a nova informação recebida e as estruturas mentais do estudante (seu conhecimento). Quando sentida, o indivíduo tende a ficar ansioso enquanto busca solucionar a sua confusão e quando não é capaz de resolvê-la, há uma alta probabilidade dele abandonar a situação, apresentando emoções de frustração e tédio (Reis, Jaques, \& Isotani, 2018).

Quando a confusão é experimentada, os estudantes precisam se envolver em atividades cognitivas para regulá-la (D’Mello et al., 2014). Essa regulação da confusão pode ser baseada em assistências relacionadas ao conhecimento, uma vez que a confusão ocorre quando há inconsistência relacionadas ao que está sendo aprendido e o que ele já sabe. Por exemplo, pode ser exibido um material multimídia (vídeo ou exemplo trabalhado) mostrando mais detalhes sobre o que está sendo ensinado ou um conhecimento prévio necessário ao estudante para resolver o problema.

Ao acessar um material de apoio por meio de elemento de multimídia (vídeo, figura ou texto), o estudante poderá relembrar ou assimilar novos conhecimentos ao seu esquema mental. Além disso, cada elemento multimídia mostra as informações de maneiras diferentes, e devem ser escolhidos adequadamente para auxiliar a cognição do estudante.

Mayer (2003) investigou como os elementos de multimídia deviam ser elaborados para auxiliar a cognição dos estudantes no processo de ensino-aprendizagem. Os resultados do seu estudo mostraram que os estudantes que eram ensinados por meio de métodos exclusivamente verbais, como a fala e a escrita, tinham mais dificuldades de memorizar o conteúdo ensinado. Isto acontece devido à transmissão do material ocorrer por dois meios (texto e imagem) que se complementam, chamado de "canal duplo". Esse canal duplo refere-se ao canal da visão e canal da audição, assumindo que os canais não são análogos e sim complementares, permitindo que os estudantes compreendam e construam conexões mais significativas do conhecimento quando os dois canais são empregados. Desta forma, é possível considerar que um elemento de interface totalmente escrito é mais complexo de ser processado cognitivamente, diferentemente de um vídeo, em que os canais de visão e audição são explorados.

Com objetivo de apoiar na escolha de qual elemento multimídia mais adequado para o estudante de acordo com o seu conhecimento, a escolha do material multimídia ocorreu por meio da análise do histórico do estudante. Foram analisados os itens de histórico (i) emoção, (ii) nível da questão, (iii) número de erros em um mesmo exercício, (iv) número de dicas solicitadas, (v) abandono do exercício anterior e (vi) número de exercícios abandonados. A emoção determina que tipo de intervenção deve ser dada; por exemplo, confusão, indica que uma intervenção deve ser dada em relação ao conteúdo ensinado que auxilie o estudante a resolver a discrepância entre o que ele está aprendendo ou sua estrutura mental ou ainda a lacuna em relação ao que ele sabe e precisa saber para resolver o problema. Os outros itens (nível da questão, número de erros em um mesmo exercício, número de dicas solicitadas, abandono do exercício anterior e número de exercícios 
abandonados) auxiliam a identificar o nível de conhecimento do estudante e o nível de dificuldade do problema. Cada item teve uma ordem de "prioridade" para determinar o impacto na escolha do elemento de multimídia (ver Figura 1). A ordem "prioridade" dos itens foi sugerida pelos autores que consideraram que alguns itens impactam mais a emoção e aumenta a probabilidade dos estudantes sentirem frustração/tédio. Quanto maior a prioridade do item, mais ele impactou na escolha.

Em relação aos elementos de multimídia, foram considerados, nesta pesquisa, quatro tipos, ordenados por grau de informação: 1-Texto, 2-Figura, 3-Vídeo e 4-Troca de exercício do mesmo nível, ilustrados na Figura 1. Quanto maior a "lacuna" entre o o conhecimento do estudante e a dificuldade da questão, mais detalhado será a explicação dada, ou seja, será escolhido um elemento multimídia que possa prover explanações mais detalhadas, com mais ilustrações e recursos (por exemplo, um vídeo demonstrando um exemplo trabalhado). No entanto, se essa diferença for pequena, uma explicação textual pequena, apenas indicando a possível causa do problema é suficiente. Esse tipo de intervenção está baseado na Teoria da Carga Cognitiva, que tem demonstrado que explicações muito detalhadas empregando diversos canais multimídia são apenas benéficas para alunos com pouco conhecimento no assunto (Sweller, 1994; Sweller, van Merriënboer, \& Paas, 2019).

Uma descrição mais detalhada desse algoritmo de intervenção pode ser encontrada em (Reis, Alvares, Jaques, \& Isotani, in press).
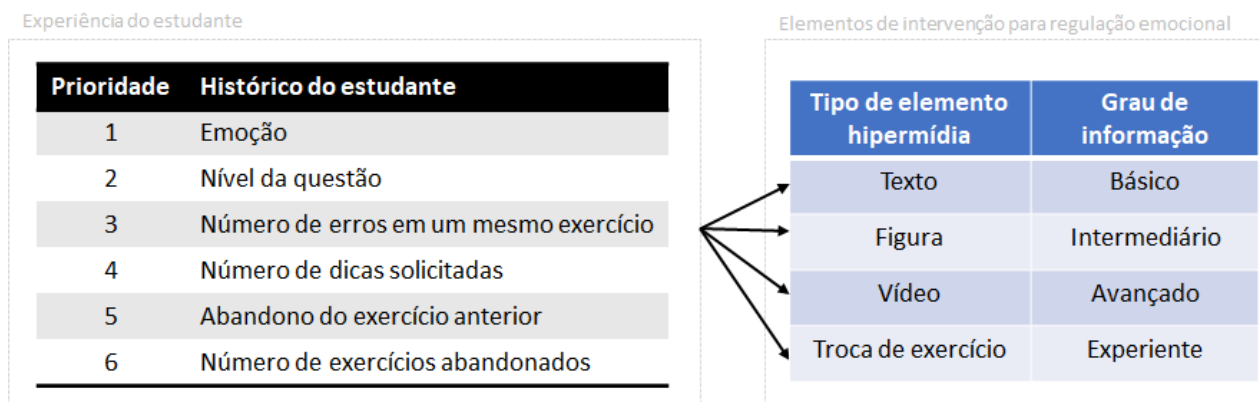

Figura 1: Proposta de intervenção de acordo com o histórico do estudante

\section{Método}

As Seções 3.1 e 3.2 descrevem a base conceitual que apoiou a criação do algoritmo para a regulação emocional em um sistema tutor inteligente (Figura 2). O algoritmo envolveu duas partes: a primeira parte consistiu em identificar o momento mais adequado em apresentar o elemento de multimídia (apresentado na Seção 3.1) e a segunda parte consistiu em selecionar o elemento multimídia mais adequado de acordo com o histórico de resolução do estudante na plataforma (apresentado na Seção 3.2). Na Figura 2, a primeira parte é representada pelo item "Calcula tempo de tolerância da confusão" e a segunda parte é representada pelos itens "Identifica histórico do estudante" e "Realiza o cálculo da escolha do elemento". Na prática, o estudante ao autorrelatar a sua confusão, o algoritmo passa a monitorar o seu tempo de tolerância da confusão (de acordo com o seu histórico e traço de personalidade - Seção 3.1), para que o estudante possa 
resolver a sua dificuldade cognitiva. Passado o tempo e caso o estudante não tenha resolvido a sua confusão, um elemento multimídia é apresentado (Seção 3.2) para auxiliar o estudante a resolver sua confusão e reduzir a probabilidade do estudante sentir frustração/tédio.

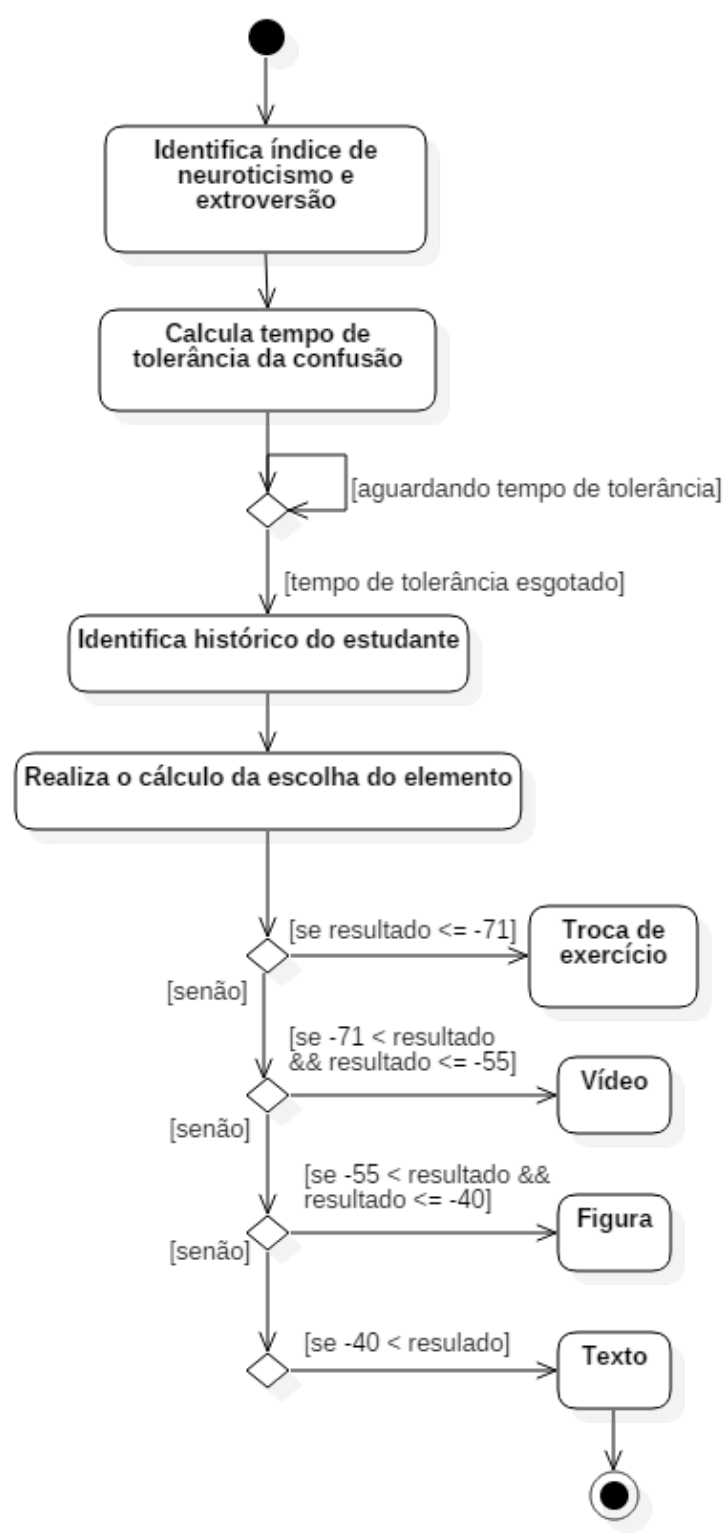

Figura 2: Funcionamento interno do algoritmo

Essa proposta foi avaliada com sujeitos separados em dois grupos: experimental e controle. No grupo experimental, os sujeitos utilizaram um STI com recurso de regulação emocional. No grupo de controle, os sujeitos utilizaram um STI sem o recurso. A avaliação teve como objetivo verificar se o estudante confuso cometia menos erros e resolveria os problemas mais rapidamente, o que estaria consequentemente diminuindo as ocorrências de emoções de frustração e tédio. Quanto mais erros o estudante comete, mais é demonstrado que a sua confusão não está sendo resolvida. Desta forma, o estudante que permanece muito tempo com o desiquilíbrio cognitivo 
possui grandes chances de sentir emoções de frustração e tédio.

\subsection{Objetivos e Hipóteses}

O propósito dessa avaliação é investigar se a regulação da confusão do estudante é efetiva. Especificamente, o objetivo é avaliar se o algoritmo para a regulação emocional que considera os traços de personalidade do estudante e o seu conhecimento prévio consegue apoiar na regulação da confusão evitando que o estudante cometa muitos erros, resultando em menos sentimentos de frustração ou tédio. Além disso, busca-se avaliar se há menos probabilidade de abandono ou pedido de dicas. Acredita-se que a regulação da emoção possibilita evitar emoções negativas (frustração ou tédio) que poderiam levar a comportamentos indesejáveis à aprendizagem, como o abandono. A partir dessa abordagem, foi formulada a seguinte pergunta geral:

$\mathbf{Q P}_{m}: \quad$ A regulação emocional baseada na personalidade do estudante e no seu conhecimento apoia o estudante a lidar com a confusão?

Assim, duas questões de pesquisa foram formuladas a partir da questão de pesquisa principal. A primeira refere-se à frequência de erros cometidos pelos estudantes durante as resoluções dos exercícios $\left(Q P_{1}\right.$ : $O$ algoritmo de regulação emocional afeta na quantidade de erros cometidos pelo estudante?). Acredita-se que os estudantes que utilizaram o STI com regulação da confusão cometeram menos erros e desta forma sentiram menos frustração ou tédio comparado aos estudantes que não possuíram auxílio da regulação emocional. Formalmente, tem-se:

- Hipótese Nula: Não há diferenças na quantidade de erros dos estudantes em ambos grupos ou a quantidade de erros do grupo que recebeu regulação emocional foi maior do que a do grupo sem regulação.

$\mathbf{H}_{0}$ : Quantidade de erros (grupo experimental) $>=$ Quantidade de erros (grupo controle) $_{\text {. }}$

- Hipótese Alternativa: Os estudantes que utilizaram o STI com regulação emocional cometeram menos erros comparado aos estudantes que não possuíram auxílio da regulação emocional.

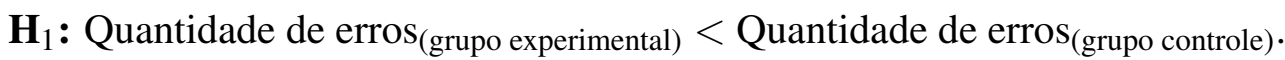

Também foi investigado o tempo usado pelos estudantes durante a resolução dos exercícios $\left(Q_{2}\right.$ : o algoritmo de regulação emocional afetou no tempo de resolução dos exercícios?). Acredita-se que o grupo que utilizou a versão do STI com suporte de regulação da confusão (grupo experimental), além de errarem menos, também resolveriam os exercícios mais rapidamente comparado com o grupo que não utilizou o sistema com apoio à regulação da confusão (grupo controle). Formalmente, tem-se:

- Hipótese Nula: Não há diferenças de tempo de resolução entre grupo dos estudantes que utilizaram o STI com regulação emocional comparado com os estudantes que utilizaram o sistema sem regulação emocional ou os estudantes que receberam regulação emocional resolveram as tarefas em um tempo maior que os estudantes sem intervenção regulatória. $\mathbf{H}_{0}:$ Tempo $_{(\text {grupo experimental })}>=$ Tempo $_{(\text {grupo controle })}$. 
- Hipótese Alternativa: Os estudantes que utilizaram o STI com regulação emocional resolveram as tarefas em menos tempo que os estudantes que utilizaram o sistema sem regulação emocional.

$$
\mathbf{H}_{1}: \text { Tempo }_{(\text {grupo experimental })}<\text { Tempo }_{\text {(grupo controle) }} \text {. }
$$

Além do relato da confusão, também foi verificado quanto à aprendizagem do estudante $\left(Q P_{3}:\right.$ O aprendizado imediato (diferença entre as notas do pré-teste e pós-teste) do grupo experimental foi superior ao grupo de controle?). Acredita-se que respeitando o tempo de tolerância da confusão que o estudante sente e intervindo antes de haver uma sobrecarga cognitiva, menos impacto há na aprendizagem, levando o estudante a melhorar o seu desempenho. Desta maneira, tem-se a terceira hipótese:

- Hipótese Nula: Não há diferenças nas notas dos estudantes em ambos grupos ou o ganho de aprendizado foi maior no grupo sem intervenção regulatória da emoção.

$\mathbf{H}_{0}$ : Aprendizado $_{\text {(grupo experimental) }}<=$ Aprendizado $_{\text {(grupo controle) }}$.

- Hipótese Alternativa: Os estudantes que utilizaram o STI com regulação emocional apresentaram maior ganho de aprendizado comparado aos estudantes que não possuíram auxílio da regulação emocional.

$\mathbf{H}_{1}$ : Aprendizado $_{\text {(grupo experimental) }}>$ Aprendizado $_{\text {(grupo controle) }}$.

Também foi verificado o abandono dos estudantes do exercício $\left(Q P_{4}: O\right.$ algoritmo de regulação emocional afeta na quantidade de abandono de exercícios pelos estudantes?). É suposto que os estudantes que tiverem apoio da regulação emocional, sentiriam menos tédio ou frustração e, consequentemente, abandonariam menos os exercícios. A partir desse contexto, temse a quarta hipótese:

- Hipótese Nula: Não há diferenças no abandono dos estudantes em ambos grupos ou houve maior abandono das atividades entre os estudantes do grupo com regulação emocional.

$\mathbf{H}_{0}$ : Abandono $_{\text {(grupo experimental) }}>=$ Abandono $_{(\text {grupo controle) }}$.

- Hipótese Alternativa: Os estudantes que utilizaram o STI com regulação emocional abandonaram menos exercícios comparado aos estudantes que não possuíram auxílio da regulação emocional.

$\mathbf{H}_{1}$ : Abandono $_{\text {(grupo experimental) }}<$ Abandono $_{(\text {grupo controle) }}$.

\subsection{Participantes}

Participaram do experimento 144 estudantes, sendo estudantes de faculdade no curso superior de Gestão Comercial em uma universidade brasileira (Média $\approx 23$ anos) e, em dois colégios particulares (Média $\approx 13.5$ anos), nas cidades de Araraquara e São Leopoldo, no Brasil, respectivamente. Ao final do experimento, os dados de 111 sujeitos puderam ser considerados por cumprir todas as fases: Pré-teste (Fase A), Intervenção (Fase B) e Pós-teste (Fase C). 


\subsection{Materiais}

Os materiais utilizados para o experimento foram: (i) teste de álgebra para o conhecimento prévio (pré-teste) em papel, (ii) questionário para identificar o traço de personalidade do estudante, (iii) questões de álgebra no STI PAT2Math e (iv) teste em papel para verificar o conhecimento pós intervenção (pós-teste). O pré-teste cobriu 20 questões abertas, envolvendo equações de primeiro grau. Estas questões foram baseadas nas questões disponíveis no PAT2Math e sugeridas por um professor de matemática. Elas foram separadas em cinco níveis: básico (3), intermediário (3), avançado (7), expert (5) e season finale (2). Cada questão correta foi atribuída ao valor de 0,05 pontos, sendo que o total do teste é 1 .

O questionário para identificar o traço de personalidade do estudante foi disponibilizado no PAT2Math e baseado no estudo de Barbosa (2009) ${ }^{5}$. Nele, o autor propõe 20 questões que podem ser respondidas na escala de 1 (Discordo totalmente) a 5 (Concordo totalmente). Cada pergunta pode ser categorizada em um dos cinco grupos: amabilidade, extroversão, realização, abertura a mudanças e neuroticismo. No final, as respostas foram somadas, e foi verificado qual grupo foi mais pontuado. Os traços de personalidade considerados neste experimento foram os índices de neuroticismo e extroversão.

A intervenção cobriu 20 questões de álgebra propostas no PAT2Math. Um grupo de estudantes utilizou uma versão sem o módulo de regulação emocional, porém com autorrelato da confusão (grupo de controle). Outro grupo utilizou a versão do sistema com a regulação emocional, também com o autorrelato, mas adicionalmente exibindo os elementos de hipermídia automaticamente de acordo com o histórico do estudante quando ele/ela autorrelatava a sua confusão (grupo experimental).

Ambos os grupos poderiam autorrelatar a sua emoção de duas maneiras (Figura 3). Na linha de inserção da resposta, um botão vermelho com ícone de interrogação (?) foi disponibilizado. Quando clicado, o estudante autorrelata a sua confusão. Para o grupo experimental, a partir desse autorrelato começava a contabilizar o seu tempo de tolerância para sentir a confusão para apresentar o elemento multimídia. A segunda maneira foi por meio de uma mensagem de alerta em tela, em que questiona se o estudante possui conhecimento para resolver o passo.

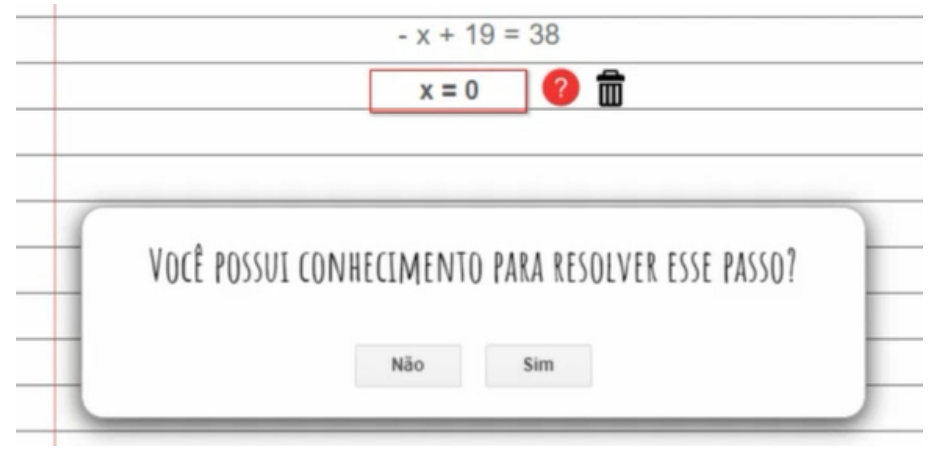

Figura 3: Autorrelato

As 20 questões envolveram equações de primeiro grau e foram separadas em cinco níveis:

\footnotetext{
${ }^{5}$ Barbosa (2009) baseou seu formulário no Big Five proposto por McCrae and John (1992), em que a personalidade é descrita como uma forma de cinco maiores dimensões. O formulário foi validado para o português.
} 
básico (3), intermediário (3), avançado (7), expert (5) e season finale (2). Assim como no préteste, cada questão correta foi atribuída ao valor de 0,05 pontos, tendo como total de pontos para cada estudante podendo atingir até 1 .

E, por fim, o pós-teste envolveu 20 questões sobre equações de primeiro grau, divididas em: básico (3), intermediário (3), avançado (7), expert (5) e season finale (2). Para cada questão correta, foi também atribuído 0,05 pontos, sendo o máximo do teste 1 .

\subsubsection{PAT2Math}

O PAT2Math (Personal Affective Tutor to Math) é um STI que auxilia no ensino de equações de $1^{\circ}$ e $2^{\circ}$ grau. Esse sistema é capaz de corrigir cada passo da resolução do problema apresentado pelo estudante, fornecer dicas e feedback sobre o seu progresso (Jaques et al., 2013).

Além disso, o PAT2Math possui um editor de álgebra chamado PATEquation, desenvolvido em JavaScript e HTML5 e é responsável pela comunicação entre o estudante e o STI (Jaques et al., 2013). Por meio deste editor, o estudante é capaz de visualizar as equações na interface gráfica, resolver as equações propostas, acessar dicas e feedbacks. A Figura 4 apresenta a interface do PATEquation, sendo: 1) lista de exercícios disponibilizadas na interface gráfica por meio de planos de aula; 2) feedback curto é apresentado quando o estudante erra; 3) dicas disponibilizadas ao estudantes quando solicitadas; 4) equação a ser resolvida; 5) passos da equação fornecidas pelos estudantes e; 6) feedback sobre a correção de cada passo.

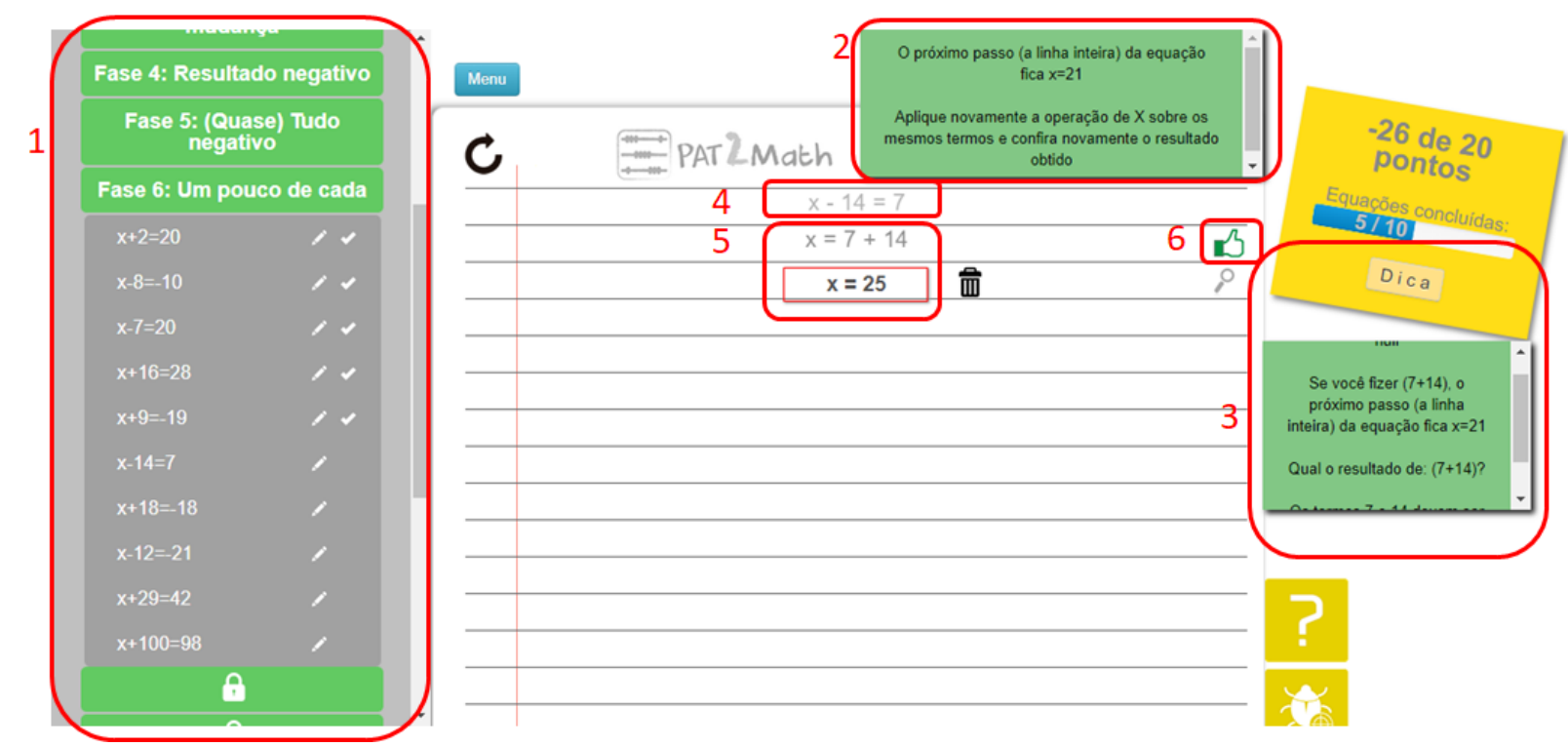

Figura 4: Tela do PAT2Math

O PATEquation corresponde ao inner loop do STI, sendo responsável por receber os passos da equação fornecida pelos estudantes, oferecer dicas e feedback para esses passos. No outer loop, as tarefas são disponibilizadas pelo tutor humano e selecionadas pelo estudante em listas de planos de aula.

A Figura 5 apresenta o funcionamento interno do módulo de regulação emocional dentro do STI de maneira mais resumida. Na iteração outer loop, o tutor virtual propõe uma tarefa (evento 
EV01). Enquanto a tarefa não é concluída, a iteração inner loop irá verificar se a emoção (evento EV02) é diferente de confuso, ou caso seja confuso, se o seu tempo de duração é inferior ao tempo que o seu traço de personalidade é capaz de tolerar. Caso essa condição seja verdadeira, o aluno poderá realizar o passo (EV03) do exercício, posteriormente o tutor irá corrigir (EV04) e irá fornece feedback da correção (EV05).

Caso o estudante esteja sentindo confusão e o seu tempo de tolerância para senti-lá se esgotou, será apresentado um elemento de multimídia para ajudar na sua reavaliação cognitiva de acordo com o seu histórico de resolução. Os elementos podem ser texto, figura, vídeo ou troca de exercício. Na hipótese do algoritmo apresentar a troca de exercício, o tutor irá propor uma nova tarefa (EV01).

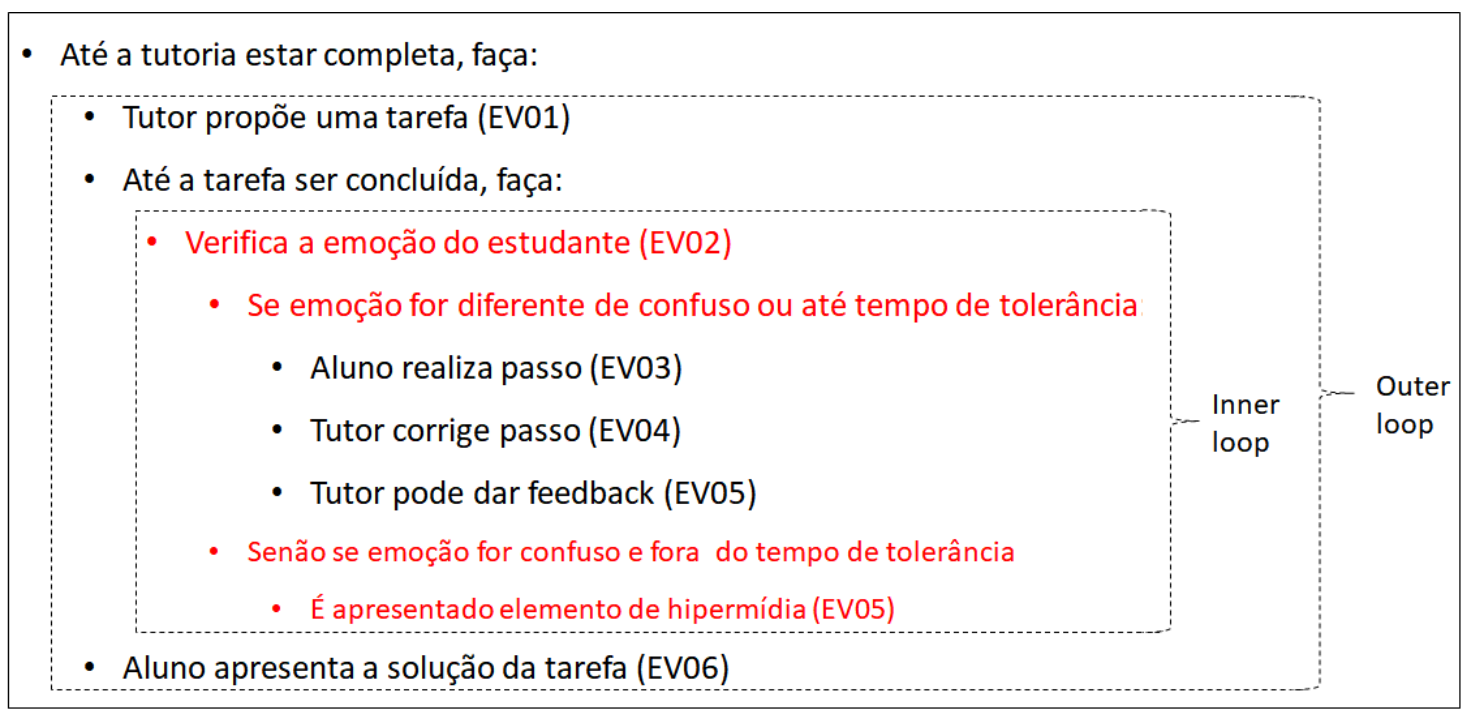

Figura 5: Funcionamento dentro do STI

A Figura 6.a e 6.b apresenta os elementos de multimídia texto e figura, respectivamente, como elementos de intervenção para a regulação emocional. É possível observar que ambos elementos possuem explicações de resolução do exercício, porém a figura apresenta os passos mais detalhados e fáceis de entender visualmente.

A Figura 7.c e 7.d apresenta os elementos de multimídia vídeo e troca de exercício, respectivamente. Foi priorizado vídeos de curta duração, com animações e áudio explicativo. $\mathrm{Na}$ troca de exercício, é exibida uma mensagem questionando se o estudante deseja tentar outra equação, seguindo a heurística "Controle e liberdade para o usuário" proposta por Nielsen (1995).

O sistema também possui um módulo especialista, que resolve as equações de $1^{\circ}$ e $2^{\circ}$ graus, corrige cada passo da resolução fornecido pelo estudante, identificadas as unidades de conhecimento utilizadas e misconceptions dos estudantes. Além disso, o sistema possui o histórico de resolução de passos, que infere conhecimento algébrico do estudante através de Redes Bayesianas Dinâmicas (Seffrin, Bittencourt, Isotani, \& Jaques, 2016). 


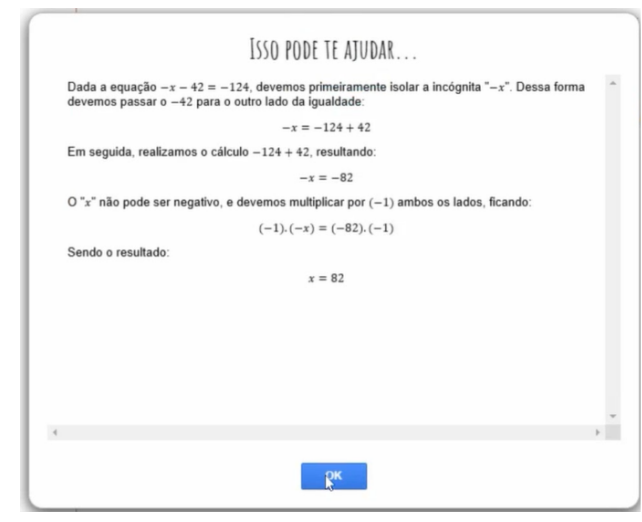

(a) Texto

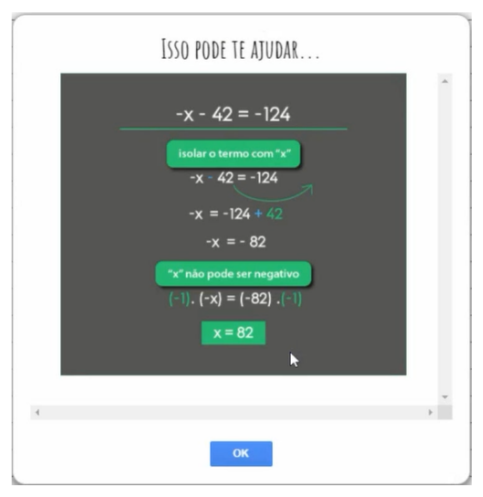

(b) Figura

Figura 6: Tela dos elementos de texto e figura para a intervenção de regulação emocional

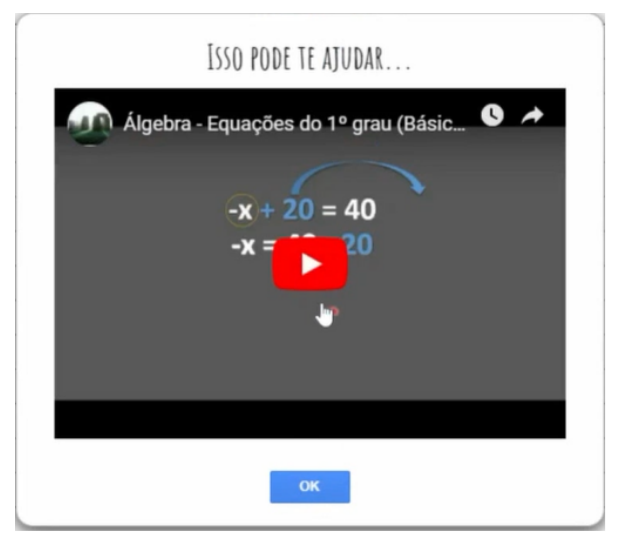

(c) Vídeo

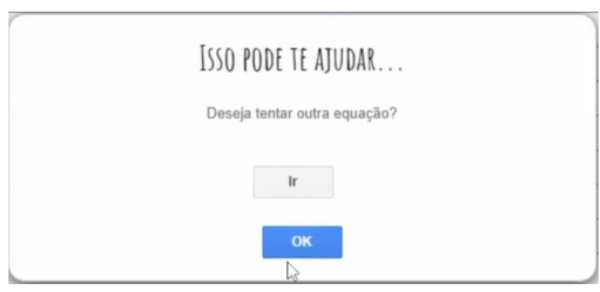

(d) Troca de exercício

Figura 7: Tela elementos de vídeo e troca de exercício para a intervenção de regulação emocional

\subsection{Procedimento}

Os sujeitos participantes do experimento foram distribuídos aleatoriamente em dois grupos (grupo experimental, com 64 sujeitos e grupo de controle, com 47 sujeitos). O grupo experimental utilizou o PAT2Math com regulação emocional e o grupo de controle utilizou o sistema sem apoio da regulação emocional. Ao aplicar o questionário dos traços de personalidade, foram identificados 69 estudantes com a personalidade extrovertida como dominante e 42 com personalidade neurótica.

Ficou disponibilizado para ambos os grupos o autorrelato da confusão. Em cada uma das escolas/faculdade, o experimento foi executado em quatro sessões, sendo uma sessão por semana: 1 sessão de pré-teste, 2 sessões de intervenção no PAT2Math no laboratório da escola e 1 sessão de pós-teste. Todos os exercícios foram os mesmos para ambos grupos. Cada sessão tinha duração de 50 minutos e foi executada em uma semana diferente (4 semanas de duração no total). A configuração do experimento conta com três fases distribuídas ao longo de quatro semanas: Fase A (Pré-teste), Fase B (Intervenção) e Face C (Pós-teste). 
- Fase A (Pré-teste): Inicialmente, os sujeitos receberam orientações oralmente sobre os objetivos e uma visão geral sobre as atividades. Dias anterior ao começo das atividades, foi enviado um termo de consentimento aprovado pelo comitê de ética, para que os pais assinassem concordando. Posteriormente, foi solicitado que os sujeitos resolvessem o teste de conhecimento em álgebra (pré-teste).

- Fase B (Intervenção): Após responder aos exercícios da Fase A, os sujeitos foram distribuídos aleatoriamente entre o grupo experimental e o grupo de controle de forma balanceada (quantidades de amostras semelhantes para cada grupo). A Fase B ocorreu no laboratório de informática da escola. Ao se autenticar no sistema, foi solicitado a todos os estudantes que respondessem ao questionário para identificar o traço de personalidade. Ao término do preenchimento do questionário de personalidade, o sistema apresentou 20 questões no PAT2Math. Além disso, foi disponibilizado, para os dois grupos, um botão e uma mensagem que era apresentada em intervalos periódicos para os estudantes autorrelatarem a sua confusão. As ações anteriores ocorreram para os dois grupos: controle e experimental. Entretanto, no grupo experimental, quando o estudante relatasse confusão, o elemento de multimídia (texto, figura ou vídeo) era apresentado. No grupo de controle, os estudantes poderiam somente relatar a sua confusão, sem a apresentação do elemento na interface.

- Fase C (Pós-teste): Por fim, os sujeitos realizaram o pós-teste.

\subsection{Resultados e Análise}

Esta seção descreve os resultados do experimento realizado e analisa se foram encontradas diferenças com significância estatística entre as versões do PAT2Math com e sem o módulo de regulação emocional. A análise estatística foi calculada usando o software SPSS v.20, Minitab 16 e Excel Office 2016.

Foram utilizados testes estatísticos paramétricos, pois foi identificada a normalidade das variáveis quantitativas de desfecho principal através do teste de Kolmogorov-Smirnov (KS) e foi concluído que existe distribuição de normalidade. Nas Tabelas a mediana é representada pela coluna "Med.", o desvio-padrão pela coluna "DP", o coeficiente de variação pela coluna "CV", o mínimo pela coluna "Min", o máximo pela coluna "Max", o número de sujeitos pela coluna "N" e a probabilidade de significância pela coluna "P-valor".

Os primeiros resultados investigam a comparação da quantidade de erros dos grupos controle e experimental, dentro do PAT2Math. Essa comparação é feita em cada um dos grupos como um todo, mas também segmentado por personalidade. A Tabela 3 apresenta a quantidade de erros cometidos por ambos grupos. Foi constatada significância entre os grupos para os traços de extrovertidos com média de 0,57 do controle e 0,44 do experimental ( $\mathrm{p}$-valor $=0,017$ ). Também há significância no grupo como um todo, em que o controle teve média de 0,56 contra 0,45 do experimental ( $\mathrm{p}$-valor $=0,007)$.

Além dos erros, também foi verificado o tempo que os estudantes demoraram para realizar as atividades dentro do PAT2Math, em ambas versões. A Tabela 4 apresenta o tempo usado pelos estudantes para a realização das atividades. Foi concluído que existe diferença média do tempo estatisticamente significante entre os grupos tanto entre os traços de extrovertidos quanto 
Tabela 3: Comparação de erros entre os grupos

\begin{tabular}{|c|c|c|c|c|c|c|c|c|c|}
\hline Erro & & Média & Med. & DP & CV & Min & Max & $\mathbf{N}$ & P-valor \\
\hline \multirow{2}{*}{ Extrovertido } & Controle & 0,57 & 0,66 & 0,24 & $42 \%$ & 0,00 & 0,93 & 25 & \multirow{2}{*}{0,017} \\
\hline & Experimental & 0,44 & 0,41 & 0,20 & $45 \%$ & 0,00 & 0,83 & 44 & \\
\hline \multirow{2}{*}{ Neurótico } & Controle & 0,55 & 0,56 & 0,21 & $39 \%$ & 0,00 & 0,87 & 22 & \multirow{2}{*}{0,278} \\
\hline & Experimental & 0,48 & 0,46 & 0,16 & $33 \%$ & 0,20 & 0,75 & 20 & \\
\hline \multirow{2}{*}{ Todos } & Controle & 0,56 & 0,58 & 0,22 & $40 \%$ & 0,00 & 0,93 & 47 & \multirow{2}{*}{0,007} \\
\hline & Experimental & 0,45 & 0,42 & 0,19 & $41 \%$ & 0,00 & 0,83 & 64 & \\
\hline
\end{tabular}

Tabela 4: Comparação do tempo entre os grupos

\begin{tabular}{lllllllll}
\hline \hline Grupos & & Média & Med. & DP & CV & Min & Max & P-valor \\
\hline \hline \multirow{2}{*}{ Extrov. } & Controle & $01: 17: 40$ & $01: 22: 04$ & $00: 17: 55$ & $23 \%$ & $00: 41: 26$ & $01: 39: 45$ & \multirow{2}{*}{$<0,001$} \\
\cline { 2 - 7 } & Experimental & $00: 54: 38$ & $00: 58: 37$ & $00: 14: 00$ & $26 \%$ & $00: 01: 29$ & $01: 18: 50$ & \\
\hline \multirow{2}{*}{ Neur. } & Controle & $01: 13: 02$ & $01: 11: 47$ & $00: 15: 18$ & $21 \%$ & $00: 37: 25$ & $01: 39: 05$ & \multirow{2}{*}{0,002} \\
\cline { 2 - 7 } & Experimental & $01: 00: 33$ & $01: 00: 55$ & $00: 07: 49$ & $13 \%$ & $00: 41: 23$ & $01: 20: 45$ & \\
\hline \multirow{2}{*}{ Todos } & Controle & $01: 15: 30$ & $01: 18: 34$ & $00: 16: 44$ & $22 \%$ & $00: 37: 25$ & $01: 39: 45$ & \multirow{2}{*}{$<0,001$} \\
\cline { 2 - 7 } & Experimental & $00: 56: 29$ & $00: 59: 03$ & $00: 12: 38$ & $22 \%$ & $00: 01: 29$ & $01: 20: 45$ & \\
\hline \hline
\end{tabular}

entre os neuróticos e, logicamente, na amostra total. Foi notado que, nas três comparações, a medida de tempo foi menor no grupo experimental em comparação ao controle, como na amostra total onde as médias foram de 56 minutos e 29 segundos e 1 hora e 15 minutos e 30 segundos, respectivamente ( $\mathrm{p}$-valor $<0,001)$.

Além disso, a variável quantidade de abandono do sistema, que foi registrada durante a intervenção (execução das versões do PAT2Math em laboratório) também foi analisada. Na variável abandono, não foi encontrada significância estatística para os diferentes grupos, como apresenta a Tabela 5 .

Tabela 5: Comparação de abandono entre os grupos

\begin{tabular}{|c|c|c|c|c|c|c|c|c|c|}
\hline Grupos & & Média & Med. & DP & CV & Min & Max & $\mathbf{N}$ & P-valor \\
\hline \multirow{2}{*}{ Extrovertido } & Controle & 2,13 & 2,17 & 0,36 & $17 \%$ & 0,61 & 2,58 & 25 & \multirow{2}{*}{0,859} \\
\hline & Experimental & 2,16 & 2,13 & 0,71 & $33 \%$ & 1,02 & 5,22 & 44 & \\
\hline \multirow{2}{*}{ Neurótico } & Controle & 2,34 & 2,14 & 0,58 & $25 \%$ & 1,58 & 4,18 & 22 & \multirow{2}{*}{0,328} \\
\hline & Experimental & 2,18 & 2,15 & 0,44 & $20 \%$ & 1,04 & 3,50 & 20 & \\
\hline \multirow{2}{*}{ Todos } & Controle & 2,23 & 2,17 & 0,48 & $22 \%$ & 0,61 & 4,18 & 47 & \multirow{2}{*}{0,568} \\
\hline & Experimental & 2,17 & 2,14 & 0,63 & $29 \%$ & 1,02 & 5,22 & 64 & \\
\hline
\end{tabular}

A diferença entre as notas do pré-teste e do pós-teste para cada grupo e personalidade também foi analisada (Tabela 6). Foi averiguado que existe diferença média entre os grupos para: extrovertido, neurótico e também para os dois grupos (Todos), porém as diferenças não são consideradas estatisticamente significantes. Foi notado que a diferença no grupo experimental foi sempre maior do que no grupo controle, mas não considerada significante, como no grupo como 
um todo, em que o ganho médio no controle foi de 1,18 contra 1,54 o experimental ( $\mathrm{p}$-valor $=$ $0,512)$.

Tabela 6: Comparação das diferenças das notas do pré-teste e pós-teste

\begin{tabular}{llllllllll}
\hline \hline Diferença & & Média & Med. & DP & CV & Min & Max & N & P-valor \\
\hline \hline \multirow{2}{*}{ Extrovertido } & Controle & 1,35 & 1,78 & 3,41 & $252 \%$ & $-8,93$ & 5,89 & 25 & \multirow{2}{*}{0,876} \\
\cline { 2 - 10 } & Experimental & 1,47 & 1,61 & 2,73 & $186 \%$ & $-5,50$ & 7,86 & 44 & \\
\multirow{2}{*}{ Neurótico } & Controle & 0,99 & 2,14 & 2,80 & $282 \%$ & $-6,07$ & 5,00 & 22 & \multirow{2}{*}{0,381} \\
\cline { 2 - 9 } & Experimental & 1,69 & 2,14 & 2,25 & $133 \%$ & $-3,64$ & 4,29 & 20 & \\
\hline \multirow{2}{*}{ Todos } & Controle & 1,18 & 2,14 & 3,11 & $263 \%$ & $-8,93$ & 5,89 & 47 & \multirow{2}{*}{0,512} \\
\cline { 2 - 9 } & Experimental & 1,54 & 1,96 & 2,57 & $167 \%$ & $-5,50$ & 7,86 & 64 & \\
\hline \hline
\end{tabular}

Apesar de não haver relevância estatística das diferenças entre as notas do pré e pós-teste dos dois grupos, nota-se que o grupo experimental neurótico possui uma leve tendência de ganho maior de aprendizado em comparação com o grupo experimental e extrovertido. Além disso, o ganho do experimental neurótico é muito superior ao grupo de controle neurótico.

\section{Discussão}

Diante da análise estatística apresentada na Seção 4.5, as questões de pesquisas da avaliação podem ser respondidas por meio da verificação das hipóteses. A primeira hipótese a ser testada refere-se à frequência de erros relatados pelos estudantes: $Q P_{1}$ : $O$ algoritmo de regulação emocional afeta na quantidade de erros cometidos pelo estudante?. A Tabela 3 indicou que o grupo de controle apresentou maior frequência de erros comparado com o grupo experimental, em comparação com ambas personalidades. Desta maneira, considerando as hipóteses formais da $\mathbf{Q P}_{1}$ é possível rejeitar a hipótese nula que afirma não existir diferenças entre as médias de erros para os grupos controle e experimental.

Em resposta formal à $\mathbf{Q} \mathbf{P}_{1}$ : Sim, o grupo experimental apresentou menos frequência de erros comparado com o grupo controle. Foi notado que o grupo experimental extrovertido apresentou uma leve frequência menor de erros do que o neurótico.

A $\mathbf{Q P} \mathbf{P}_{2}$ refere-se ao tempo usado por ambos grupos e traços de personalidade $\left(Q P_{2}: o\right.$ algoritmo de regulação emocional afetou no tempo de resolução dos exercícios?). Os resultados apresentados na Tabela 4 sugerem que houve uma diferença média entre os grupos e traços de personalidade, em que o grupo experimental com traços de personalidade de extroversão realizaram os exercícios em menos tempo. Além deste grupo errar menos, o tempo usado também foi menor para a resolução. Desta maneira, considerando as hipóteses formais da $\mathbf{Q P}_{2}$ é possível rejeitar a hipótese nula que afirma não existir diferenças entre as médias de tempo para os grupos controle e experimental.

Em resposta formal à $\mathbf{Q P}_{2}$ : Sim, o grupo experimental usou menos tempo para a resolução dos exercícios comparado com o grupo controle.

A $Q P_{3}$ refere-se ao aprendizado imediato (diferença entre as notas do pré-teste e do pós- 
teste). Os resultados apresentados na Tabela 6 sugerem que existe uma diferença média entre os grupos e personalidades, porém elas não foram consideradas estatisticamente relevantes. Entretanto, foi observado que existe uma tendência de ganho de aprendizado para o grupo experimental, particularmente para a personalidade neurótico. Desta maneira, não é possível refutar a hipótese nula que afirma que o aprendizado imediato de ambos grupos foram iguais.

Em resposta à $Q P_{3}: O$ aprendizado imediato (diferença entre as notas do pré-teste $e$ pós-teste) do grupo experimental foi superior ao grupo de controle?, não há evidências que a intervenção de regulação emocional aplicada tenha influenciado a aprendizagem do grupo experimental, que recebeu a intervenção.

Além de observar o aprendizado, também foi analisada a quantidade de abandono dos estudantes do PAT2Math durante a resolução dos exercícios $\left(Q P_{4}: O\right.$ algoritmo de regulação emocional afeta na quantidade de abandono de exercícios pelos estudantes?). De acordo com os resultados (Tabela 5), não foi encontrada significância estatística para os diferentes grupos e personalidades. Desta forma, não é possível refutar a hipótese nula. Assim, em resposta formal à $Q P_{4}$ : Não, a quantidade de abandono do grupo experimental foi muito semelhante à quantidade de abandono do grupo de controle. Ou seja, o algoritmo não influenciou os estudantes a permanecerem no PAT2Math.

Com todas as análises descritas, é possível responder a pergunta de pesquisa geral $\boldsymbol{Q P}_{m}$ : $O$ algoritmo de regulação emocional apoia o estudante a lidar com a confusão?. Os resultados indicam que os estudantes que utilizaram a versão do PAT2Math com o algoritmo implementado cometeram menos erros e realizaram os exercícios em menos tempo, porém não afetando na frequência de abandono ou no aprendizado imediato. Desta maneira, acredita-se que a diminuição de erros e tempo minimizou a probabilidade dos estudantes sentirem frustração e tédio, resultando em uma regulação da confusão de forma adequada.

\section{Ameaças à Validade}

A quantidade de sujeitos $(\mathrm{N}=111)$ da amostra para a análise final pode não ter sido a ideal, sendo necessário aumentar a quantidade de participantes para obter resultados estatisticamente significantes para o aprendizado imediato e quantidade de abandono. Outra ameaça observada é o questionário de autorrelato da confusão. $\mathrm{O}$ estudante pode não ter relatado sua confusão sempre quando ela ocorreu. Além disso, o estudante pode ter relatado a sua confusão quando o tempo de tolerância dessa emoção já estava terminando, o que pode implicar nos resultados do experimento.

\section{Conclusão}

A confusão é uma emoção importante no processo de ensino-aprendizagem, pois dependendo de como é gerenciada, pode levar o estudante a se sentir engajado nas atividades escolares ou abandonar o aprendizado do material proposto (D’Mello, Graesser, et al., 2007). Quando sentida, o estudante precisa se envolver em atividades cognitivas relacionadas ao seu conhecimento e assimilação de novas informações para resolvê-la, com objetivo de reduzir a quantidade de erros 
cometidos e consequentemente os sentimentos de frustração e tédio.

Diante de sua importância, o estudo de Reis, Jaques, and Isotani (2018) investigou a influência do conhecimento prévio e os traços de personalidade no tempo de permanência entre os estados emocionais de confusão e frustração/tédio no processo de aprendizagem. Os resultados desse estudo sugerem que estudantes com alto índice de neuroticismo e baixa nota de conhecimento de álgebra não conseguem lidar muito bem com a confusão, permanecendo menos tempo nesta emoção, comparado com os estudantes com alto índice de extroversão e baixo desempenho no conhecimento de álgebra. Isto significa que o estudante neurótico e iniciante em álgebra permanece menos tempo na emoção confusão e sente mais rapidamente frustração/tédio se comparado com estudantes extrovertidos com o mesmo nível de conhecimento em álgebra. Além disso, os autores sugerem um cálculo para determinar o tempo que cada perfil de estudante consegue tolerar a confusão.

Esgotado o tempo de confusão, o estudante precisa regular a sua emoção para que não seja modificada em frustração/tédio, que são emoções que impactam negativamente o aprendizado. Essa regulação deve ser baseada em assistências relacionadas ao conhecimento, como por exemplo, a apresentação de um elemento multimídia: um texto, vídeo ou figura que apoia o estudante a identificar seus problemas cognitivos e relembre os conceitos aprendidos em sala de aula. Essa assistência também deve considerar o histórico de interação do estudante. Quando um estudante está sentindo confusão e cometendo vários erros durante a resolução de um problema, possui grandes chances de sentir frustração ou tédio. Portanto, a cada erro cometido pelo estudante, a assistência por meio de elemento de multimídia deve ser mais informativa (por exemplo, intervenção vídeo que faz o uso de áudio e imagem), com o intuito de evitar que o estudante siga confuso e que ele consiga resolver o exercício proposto. Desta forma, é preciso entender em como escolher o elemento multimídia de acordo com o histórico do estudante e qual item desse histórico influencia na escolha do elemento.

Para apoiar a escolha do elemento multimídia mais adequado para assistir a confusão do estudante, um algoritmo foi proposto. Nele, o histórico de interação do estudante no sistema é considerado, como o nível da questão atual, número de acertos e abandonos, além do traço de personalidade. Com esses dados, o algoritmo baseado em um modelo probabilístico (ver Seção 3.2), determina qual é o melhor elemento multimídia que deve ser apresentado ao estudante. Os elementos de multimídia são divididos de acordo com os níveis de detalhamento, sendo eles texto, figura, vídeo e a troca do exercício. Por exemplo, o elemento de vídeo tem como objetivo ser uma assistência de mais fácil entendimento e detalhado, pois contém uma explicação escrita e falada, em comparação com um elemento somente textual.

Neste algoritmo, quando a confusão do estudante é detectada (por meio de detectores ou autorrelato), o elemento de multimídia é apresentado ao estudante ao fim do seu tempo de tolerância em sentir a emoção. Assim, é possível permitir que o estudante consiga buscar o seu conhecimento durante a sua confusão por meio da construção de mapas cognitivos, entretanto minimizando emoções que impactam negativamente no seu aprendizado, como frustração e tédio. Esse algoritmo pode guiar desenvolvedores e pesquisadores de STIs na elaboração e desenvolvimento de sistemas educacionais com regulação emocional personalizada, com objetivo de ganhos na aprendizagem e uma possibilidade de evitar o "Gaming the System" (Baker, Corbett, Koedinger, \& Wagner, 2004; Nunes, Jaques, Pós-graduação, \& Aplicada, 2013). 
Ao final, o algoritmo foi avaliado com 111 estudantes do ensino fundamental e superior em sala de aula. Os estudantes foram divididos em duas equipes: grupo experimental que possuiu o módulo de regulação emocional e o grupo de controle que usou o PAT2Math sem o módulo de regulação emocional. Observamos que os estudantes do grupo experimental e personalidade neurótico cometerem menos erros e realizaram os exercícios em menos tempo, porém não resultou em menos abandono do sistema ou maior aprendizado. Por estes resultados, respondemos a nossa principal questão de pesquisa: $(Q P m)$ : A regulação emocional apoia o estudante a lidar com a confusão?, em que estratégias que consideram o histórico do estudante (nível da questão atual, número de acertos, abandonos, dicas) e traço de personalidade é capaz de fazer com que estudantes errem menos e melhorem seu desempenho em relação ao tempo, e, consequentemente, reduzir sentimentos de frustração/tédio em relação a problemas de resolução de exercícios.

Escolher estratégias para regular a confusão considerando os traços de personalidade e conhecimento prévio do estudante é difícil. A maior parte dessa complexidade está relacionada à tarefa de selecionar estratégias apropriadas que estimulem o estudante a se atentarem aos elementos de multimídias disponíveis como materiais de apoio. Acreditamos que o algoritmo pode ajudar designers e profissionais a implementarem a regulação da confusão para as personalidades extrovertida e neurótica. Entretanto, é recomendado que seja aplicado mais experimentos com o algoritmo com diversos públicos. Dado o foco da pesquisa aqui descrita, apesar do tamanho e das características da amostra investigada, as informações extraídas do estudo foram significativas e nos deu evidências de que o nosso algoritmo é viável e propício.

\section{Referências}

Allport, G. W., \& Leite, D. M. (1966). Personalidade: padrões e desenvolvimento. Editora Herder. [GS Search]

Arguedas, M., Daradoumis, T., \& Xhafa, F. (2016). Analyzing the effects of emotion management on time and self-management in computer-based learning. Computers in Human Behavior, 63, 517-529. doi: http://dx.doi.org/10.1016/j.chb.2016.05.068 [GS Search]

Baker, R. S. J. D., Corbett, A. T., Koedinger, K. R., \& Wagner, A. (2004). Off-Task Behavior in the Cognitive Tutor Classroom: When Students Game The System. In Acm chi 2004: Computer-human interaction (pp. 383-390). doi: http://dx.doi.org/10.1145/985692.985741 [GS Search]

Bakhtiar, A., Webster, E. A., \& Hadwin, A. F. (2018). Regulation and socio-emotional interactions in a positive and a negative group climate. Metacognition and Learning, 13(1), 57-90. doi: http://dx.doi.org/10.1007/s11409-017-9178-x [GS Search]

Barbosa, A. (2009). Modelo hierárquico de fobias infanto-juvenis: testagem e relação com os estilos maternos. Tese de Doutorado. Tese (Doutorado em Ciência da Computação). [GS Search]

Bosse, T., Gerritsen, C., De Man, J., \& Treur, J. (2012). Measuring stress-reducing effects of virtual training based on subjective response. In International conference on neural information processing (pp. 322-330). doi: http://dx.doi.org/10.1007/978-3-642-34475-639 [GS Search]

Cattell, R. B., \& P. Cattell, H. E. (1995). Personality structure and the new fifth edition 
of the 16pf. Educational and Psychological Measurement, 55(6), 926-937. doi: http://dx.doi.org/10.1177/0013164495055006002 [GS Search]

Craig, S., Graesser, A., Sullins, J., \& Gholson, B. (2004). Affect and learning: an exploratory look into the role of affect in learning with autotutor. Journal of educational media, 29(3), 241-250. doi: http://dx.doi.org/10.1080/1358165042000283101 [GS Search]

Desseilles, M. (2016). Perspectives on games, computers, and mental health: Questions about paradoxes, evidences, and challenges. Frontiers in psychiatry, 7, 122 . doi: http://dx.doi.org/10.3389/fpsyt.2016.00122 [GS Search]

D’Mello, S., \& Calvo, R. A. (2013). Beyond the basic emotions: what should affective computing compute? In Chi '13 extended abstracts on human factors in computing systems on (p. 2287). New York, New York, USA: ACM Press. doi: 10.1145/2468356.2468751 [GS Search]

D’Mello, S., Graesser, A., et al. (2007). Monitoring affective trajectories during complex learning. In Proceedings of the annual meeting of the cognitive science society (Vol. 29). [GS Search]

D’Mello, S., Person, N. K., \& Lehman, B. (2009). Antecedent-consequent relationships and cyclical patterns between affective states and problem solving outcomes. In Aied (pp. 5764). NLD: IOS Press. [GS Search]

D’Mello, S., Picard, R. W., \& Graesser, A. (2007). Toward an affect-sensitive autotutor. IEEE Intelligent Systems, 22(4). doi: http://dx.doi.org/10.1109/MIS.2007.79 [GS Search]

D’Mello, S., Lehman, B., Pekrun, R., \& Graesser, A. (2014). Confusion can be beneficial for learning. Learning and Instruction, 29, 153-170. doi: http://dx.doi.org/10.1016/j.learninstruc.2012.05.003 [GS Search]

Estrada, C. A., Isen, A. M., \& Young, M. J. (1994). Positive affect improves creative problem solving and influences reported source of practice satisfaction in physicians. Motivation and emotion, 18(4), 285-299. doi: http://dx.doi.org/10.1007/BF02856470 [GS Search]

Gaggioli, A., Raspelli, S., Grassi, A., Pallavicini, F., Cipresso, P., Wiederhold, B. K., \& Riva, G. (2011). Ubiquitous health in practice: the interreality paradigm. In Mmvr (pp. 185-191). [GS Search]

Graesser, A. C., Chipman, P., Haynes, B. C., \& Olney, A. (2005). AutoTutor: An intelligent tutoring system with mixed-initiative dialogue. IEEE Transactions on Education, 48(4), 612-618. doi: http://dx.doi.org/10.1109/TE.2005.856149 [GS Search]

Greenleaf, R. (2002). The adolescent brain: Still ready to learn. Principal Leadership, 2(8), 24-28. [GS Search]

Gross, J. J. (1998). Antecedent-and response-focused emotion regulation: divergent consequences for experience, expression, and physiology. Journal of personality and social psychology, 74(1), 224. doi: http://dx.doi.org/10.1037//0022-3514.74.1.224 [GS Search]

Jaques, P. A., Seffrin, H., Rubi, G., de Morais, F., Ghilardi, C., Bittencourt, I. I., \& Isotani, S. (2013). Rule-based expert systems to support step-by-step guidance in algebraic problem solving: The case of the tutor pat2math. Expert Systems with Applications, 40(14), 54565465. doi: http://dx.doi.org/10.1016/j.eswa.2013.04.004 [GS Search]

Kabat-Zinn, J., Wheeler, E., Light, T., Skillings, A., Scharf, M. J., Cropley, T. G., ... Bernhard, J. D. (1998). Influence of a mindfulness meditation-based stress reduction intervention on rates of skin clearing in patients with moderate to severe psoriasis undergoing photo therapy (uvb) and photochemotherapy (puva). Psychosomatic medicine, 60(5), 625-632. [GS Search] 
Lazarus, R. S. (1993). From psychological stress to the emotions: A history of changing outlooks. Annual review of psychology, 44(1), 1-22. doi: http://dx.doi.org/10.1146/annurev.ps.44.020193.000245 [GS Search]

Lehman, B., D’Mello, S., Strain, A., Mills, C., Gross, M., Dobbins, A., ... Graesser, A. (2013). Inducing and tracking confusion with contradictions during complex learning. International Journal of Artificial Intelligence in Education, 22(1-2), 85-105. doi: http://dx.doi.org/10.3233/JAI-130025 [GS Search]

Linnenbrink, E. A., \& Pintrich, P. R. (2000). Multiple pathways to learning and achievement: The role of goal orientation in fostering adaptive motivation, affect, and cognition. Intrinsic and extrinsic motivation: The search for optimal motivation and performance, 195-227. doi: http://dx.doi.org/10.1016/B978-012619070-0/50030-1 [GS Search]

Mayer, R. E. (2003). The promise of multimedia learning: using the same instructional design methods across different media. Learning and instruction, 13(2), 125-139. doi: http://dx.doi.org/10.1016/S0959-4752(02)00016-6 [GS Search]

McCrae, R. R., \& John, O. P. (1992). An introduction to the five-factor model and its applications. Journal of Personality, 60(2), 175-215. doi: http://dx.doi.org/10.1111/j.14676494.1992.tb00970.x [GS Search]

Nararro-Haro, M. V., Hoffman, H. G., Garcia-Palacios, A., Sampaio, M., Alhalabi, W., Hall, K., $\&$ Linehan, M. (2016). The use of virtual reality to facilitate mindfulness skills training in dialectical behavioral therapy for borderline personality disorder: a case study. Frontiers in psychology, 7, 1573. doi: http://dx.doi.org/10.3389/fpsyg.2016.01573 [GS Search]

Nielsen, J. (1995). 10 usability heuristics for user interface design. Nielsen Norman Group, 1(1). [GS Search]

Nunes, T. M., Jaques, P. A., Pós-graduação, P. D., \& Aplicada, C. (2013, nov). Analisando a influência da presença de um Agente Pedagógico Animado em relação ao Gaming The System. In M. C. C. Baranauskas, R. Bonacin, M. A. F. Borges, \& C. G. da Silva (Eds.), Simpósio brasileiro de informática na educação - cbie (pp. 758-767). SBC. doi: http://dx.doi.org/10.5753/CBIE.SBIE.2013.758 [GS Search]

Oxford, R. L., \& Bolaños-Sánchez, D. (2016). A tale of two learners: Discovering mentoring, motivation, emotions, engagement, and perseverance. In New directions in language learning psychology (pp. 113-134). Springer. doi: http://dx.doi.org/10.1007/978-3-31923491-58 [GS Search]

Pallavicini, F., Gaggioli, A., Raspelli, S., Cipresso, P., Serino, S., Vigna, C., ... others (2013). Interreality for the management and training of psychological stress: study protocol for a randomized controlled trial. Trials, 14(1), 191. doi: http://dx.doi.org/10.1186/1745-621514-191 [GS Search]

Pessoa, L. (2008). On the relationship between emotion and cognition. Nature reviews neuroscience, 9(2), 148. doi: http://dx.doi.org/10.1038/nrn2317 [GS Search]

Reis, H., Alvares, D., Jaques, P., \& Isotani, S. (2018). Analysis of permanence time in emotional states: A case study using educational software. In International conference on intelligent tutoring systems (pp. 180-190). doi: http://dx.doi.org/10.1007/978-3-319-91464-018 [GS Search]

Reis, H., Alvares, D., Jaques, P., \& Isotani, S. (in press). A proposal of model of emotional regulation in intelligent learning environments.

Reis, H., Jaques, P. A., \& Isotani, S. (2018, sep). Sistemas Tutores Inteligentes que Detectam as 
Emoções dos Estudantes: um Mapeamento Sistemático. Revista Brasileira de Informática na Educação, 26(3), 76. doi: http://dx.doi.org/10.5753/rbie.2018.26.03.76 [GS Search]

Rodrigo, M. M. T., Baker, R. S., \& Nabos, J. Q. (2010). The relationships between sequences of affective states and learner achievement. In Proceedings of the 18th international conference on computers in education (pp. 56-60). [GS Search]

Rozin, P., \& Cohen, A. B. (2003). Reply to commentaries: Confusion infusions, suggestives, correctives, and other medicines. American Psychological Association, 3(1), 92-96. doi: http://dx.doi.org/10.1037/1528-3542.3.1.92 [GS Search]

Scherer, K. R. (2005). What are emotions? and how can they be measured? Social Science Information, 44(4), 695-729. doi: https://doi.org/10.1177/0539018405058216 [GS Search]

Schutz, P. A., \& Lanehart, S. L. (2002). Introduction: Emotions in education. Educational Psychologist, 37(2), 67-68. [GS Search]

Seffrin, H., Bittencourt, I. I., Isotani, S., \& Jaques, P. A. (2016). Modelling students' algebraic knowledge with dynamic bayesian networks. In Advanced learning technologies (icalt), 2016 ieee 16th international conference on (pp. 44-48). doi: http://dx.doi.org/10.1109/ICALT.2016.96 [GS Search]

Sutton, R. E., \& Wheatley, K. F. (2003). Teachers' emotions and teaching: A review of the literature and directions for future research. Educational psychology review, 15(4), 327358. doi: http://dx.doi.org/10.1023/A:1026131715856 [GS Search]

Sweller, J. (1994, jan). Cognitive load theory, learning difficulty, and instructional design. Learning and Instruction, 4(4), 295-312. doi: http://dx.doi.org/10.1016/09594752(94)90003-5 [GS Search]

Sweller, J., van Merriënboer, J. J. G., \& Paas, F. (2019, jan). Cognitive Architecture and Instructional Design: 20 Years Later. Educational Psychology Review, 10(3), 251-296. doi: http://dx.doi.org/10.1007/s10648-019-09465-5 [GS Search]

Thompson, R. A. (1991). Emotional regulation and emotional development. Educational Psychology Review, 3(4), 269-307. doi: http://dx.doi.org/10.1007/BF01319934 [GS Search]

Tian, F., Gao, P., Li, L., Zhang, W., Liang, H., Qian, Y., \& Zhao, R. (2014). Recognizing and regulating e-learners' emotions based on interactive chinese texts in e-learning systems. Knowledge-Based Systems, 55, 148-164. doi: http://dx.doi.org/10.1016/j.knosys.2013.10.019 [GS Search]

VanLehn, K. (2011). The relative effectiveness of human tutoring, intelligent tutoring systems, and other tutoring systems.

Xu, J., Du, J., \& Fan, X. (2013). Individual and group-level factors for students' emotion management in online collaborative groupwork. The internet and higher education, 19, 1-9. doi: http://dx.doi.org/10.1016/j.iheduc.2013.03.001 [GS Search] 